\title{
Variability of Stem-Base Infestation and Coexistence of Fusarium spp. Causing Crown Rot of Winter Wheat in Serbia
}

\author{
Radivoje Jevtić ${ }^{1 *}$, Nemanja Stošić ${ }^{2}$, Vesna Župunski ${ }^{1}$, Mirjana Lalošević ${ }^{1}$, and Branka Orbović ${ }^{1}$ \\ ${ }^{1}$ Institute of Field and Vegetable Crops, 21000 Novi Sad, Serbia \\ ${ }^{2}$ Faculty of Agriculture, University of Novi Sad, 21000 Novi Sad, Serbia
}

(Received on February 21, 2019; Revised on June 29, 2019; Accepted on September 9, 2019)

Investigations related with factors influencing root and crown rot are rare and mainly related to farming practice and soil management. The main objective of this study was to examine broader range of factors influencing stem-base infestation of winter wheat in the field conditions. The effect of spatial distribution of infected plants on disease index (DIs) assessments was also investigated. Analysis of factors influencing DIs of crown rot of wheat demonstrated significant influence of the growing seasons $(P<0.001)$ and extreme fluctuations in winter temperatures $(P<0.001)$. In addition to that, localities together with their interaction with the growing season also significantly influenced DIs $(P<0.001)$. Aggregation of infected plants influenced variability of DI estimations, and it was pointed out that more extensive investigation should be conducted on broad range of DI in order to establish sampling method giving uniform sampling precision. Fusarium graminearum was shown to be predominant Fusarium species in Serbia (72.6\%) using sequence-characterized amplified region analysis. Interestingly $F$. oxysporum was isolated in higher frequencies $(\mathbf{2 7 . 4 \% )}$ ) than it was reported in the literature. Given that there were no reports on the diversity of Fusarium species causing crown rot of wheat in Serbia, this study presents first report on this important

\footnotetext{
*Corresponding author.

Phone) +381-21-4898200, FAX) +381-21-4898222

E-mail) radivoje.jevtic@ifvens.ns.ac.rs

ORCID

Radivoje Jevtić

https://orcid.org/0000-0001-8069-0862

(c) This is an Open Access article distributed under the terms of the Creative Commons Attribution Non-Commercial License (http:// creativecommons.org/licenses/by-nc/4.0) which permits unrestricted noncommercial use, distribution, and reproduction in any medium, provided the original work is properly cited.
}

Articles can be freely viewed online at www.ppjonline.org. subject. It also indicated that more attention should be focused on combined effects of abiotic and biotic factors influencing stem-base infestation of winter wheat. This knowledge will contribute to better understanding of factors influencing root and crown rot of wheat which would ensure sustainable disease management in the future.

Keywords : climate change, crown rot, Fusarium, wheat

Handling Editor : Jeon, Junhyun

Root and crown rot are known as economically important diseases of cereal crops causing yield losses up to $50 \%$ (Agrios, 1997; Smiley et al., 2005). Since various fungal species cause discoloration of roots and crowns of wheat on the same plant and the same field, root and crown rot are considered a disease complex (Fernandez and Conner, 2011; Matusinsky et al., 2008). The most common Fusari$u m$ spp. associated with root and crown rot of wheat are $F$. pseudograminearum, $F$. culmorum, and $F$. graminearum (Fernandez and Conner, 2011; Xu et al., 2018). However, there are also many other fungal species reported as causal agents of crown and root rot such as: $F$. acuminatum, $F$. avenaceum, $F$. crookwellense, $F$. poae, Microdochium vars. nivale and majus (brown foot rot); Oculimacula yallundae and O. acuformis (eyespot); Bipolaris sorokiniana (common root rot); Gaeumannomyces graminis and G. graminis var. tritici (take-all) and Rhizoctonia spp. (sharp eyespot) (Fernandez and Conner, 2011; Matusinsky et al., 2008; Xu et al., 2018).

Geographic distribution of causal agents of root and crown rot is mainly associated with climatic conditions, wheat varieties, farming practices (conventional/organic), soil management, and the preceding crop (Matusinsky et al., 2008; Xu et al., 2018). F. pseudograminearum was 
reported as dominant species in the arid zones of the Pacific Northwest and Australia (Poole et al., 2013). On the other hand, F. culmorum was predominant in the cooler, higher altitude and high rainfall areas (Smiley et al., 2005).

$F$. graminearum was reported to be dominant in eastern Australia and southern Europe (Xu et al., 2018). Bipolaris sorokiniana was reported to be prevalent in the arid and semi-arid areas (Smiley and Patterson, 1996), while takeall and sharp eyespot are most severe in wet areas or during the wet years and in irrigated fields (Paulitz, 2010). Although root and crown rot is considered a disease complex, interactions and antagonistic effects among different causal agents are hardly known. There are different reports on prevalence and combinations of species (Fusarium spp., $B$. sorokiniana, $R$. cerealis, and $G$. graminis var. tritici) recovered from wheat roots or stems from the same plant or the same field (Xu et al., 2018). As a result, additional studies in different geographic regions and growing conditions are needed in order to elucidate factors that influence risk of root and crown rot outbreaks.

Although Fusarium species are causal agents of Fusarium head blight (FHB) and Fusarium crown and root rot (FCR, FRR), the focus on investigations of FHB disease management was greater than those of FCR and FRR (Smiley et al., 2005; Wang et al., 2015). In Serbia, there are only few reports related to causal agents on root and crown rot on wheat (Stošić et al., 2016). The last survey on occurrence of causal agents of root and crown rot of wheat was conducted in 2004/2005 growing season on eight locations in Serbia where plant deterioration was recorded at various stages of wheat crop development (Jevtić et al., 2006). The results of the survey showed that the genus Fusarium (55.2\%) was responsible for the outbreak of root and stem base rot of wheat. In addition, G. graminis $(1.1 \%)$ and Pseudocercosporella herpotrichoides $(0.7 \%)$ were present at low levels. Until now, there were no reports on which Fusarium species predominates as causal agent of FRR and FCR in Serbia, although it was reported that $F$. graminearum predominates as causal agent of FHB (Lević et al., 2012). In addition, Serbia is facing with increment of frequency, intensity, and duration of periods with extreme climatic conditions which were reported to be climate change manifestations worldwide (Westra et al., 2014). As a result, the main objective of this study was to examine: (1) factors influencing stem-base infestation of winter wheat in the field conditions under changing climate and (2) the diversity of Fusarium species causing FCR under extreme climatic conditions since those species could serve as persistent source of inoculum and represent potential threat on wheat production under changing climate in Serbia.

\section{Material and Methods}

Survey protocol. The results of this study originated from the survey conducted on wheat-growing areas in 16 locations belonging to Mačva District (northwest of Central Serbia) during 2013/2014 and 2016/2017 growing seasons. Distance between fields was minimum $3 \mathrm{~km}$. Plants in each field were sampled in four replicates (subsamples) that have been taken at four different sides of the field with minimum distance of $20 \mathrm{~m}$ between them, where each sampling spot was at least $10 \mathrm{~m}$ from the margin of the field. Each subsample was consisted of 50 plants taken from 0.5 $\times 0.5 \mathrm{~m}$ plots. Sampling was conducted immediately after the harvest (BBCH 99 - harvested product) knowing that the different causal agents of crown rot can exhibit pathogenicity at different growth stage of wheat (Matusinsky et al., 2008). Survey was performed on the fields which were arbitrarily chosen from collaborative growers without prior knowledge of current disease incidence or severity. Since it was reported that crop rotations showed almost no significant differences in terms of eyespot and Fusarium foot rot disease incidence when investigated within individual sites and years (de Mol et al., 2018), cropping history was not considered as a factor.

Stem-base infestation assessment. Crop damage assessment was made after the sampling. The whole complex of brown discolored spots on the first internode was recorded using the scale from 0 to 9 as follows: 0 , no infected internode; $1,1-10 \%$ infected internode, 2 , $11-20 \%$ infected internode; $3,21-30 \%$ infected internode; 4 , $31-40 \%$ infected internode; $5,41-50 \%$ infected internode; 6 , $51-60 \%$ infected internode; $7,61-70 \%$ infected internode; $8,71-80 \%$ infected internode; and $9,>81 \%$ infected internode. This scale is modification of crown rot rating scale reported by Wildermuth and McNamara (1994).

An internode disease index (DI) was calculated using Townsend-Heuberger formula (Townsend and Heuberger, 1943):

$$
\mathrm{DI}(\%)=\left(\sum(n \times v) /(i \times N)\right) \times 100
$$

, where, $v$ is class of infection, $i$ is highest class of infection (9 in this case), $n$ is number of plants in each class, and $N$ is total amount of plants.

Isolation and classical identification of Fusarium species causing FCR. The plants assessed for the level of stembase infestation and with symptoms characteristic for $\mathrm{Fu}$ - 
sarium, Gaeumannomyces, and Oculimacula were selected for further isolation and identification of causal agents of crown rot. Segments of $5 \times 5 \mathrm{~mm}$ were removed from the basal part of the first internodes of the selected wheat tillers and were used to assess fungal pathogen species by culturing on a general media of $20 \%$ potato dextrose agar (PDA, potato $200 \mathrm{~g}$, dextrose $20 \mathrm{~g}$, agar $15 \mathrm{~g}$ ) amended with lactic acid PDA. Prior to plating, stem segments were disinfected in sodium hypochlorite at $1 \%$ for $2 \mathrm{~min}$ and rinsed three times in sterile distilled water for 2 min every time. Five disinfected segments were placed on Water agar media amended with streptomycin sulfate as well as on PDA Agar (HiMedia, Einhausen, Germany) in order to identify predominant fungal species as causal agents of crown rot. Plates were incubated at $24 \pm 1^{\circ} \mathrm{C}$. Resulting fungal colonies were purified by single-spore isolation prior to final identification and DNA extraction. The identification based on morphological characteristics was performed using the keys of Barnett and Hunter(1972) and Leslie and Summerell (2006).

Molecular identification of Fusarium species by species-specific PCR (sequence-characterized amplified region analysis). Molecular identification of Fusarium species was made on isolates collected in growing season 2016/2017 in order to identify diversity of Fusarium species causing crown rot under extreme/unfavorable climatic conditions. DNA of all Fusarium isolates was extracted using the procedure of Möller et al. (1992). Briefly, 10\% cetyltrimethylammoniumbromid, Proteinase K, and SEVAG (chloroform:isoamyl alcohol, 24:1, v/v) were used for DNA isolation. DNA was precipitated using isopropanol, re-suspended in $0.1 \times$ TRIS-EDTA buffer and stored at $-20^{\circ} \mathrm{C}$.

Isolates that were identified as $F$. graminearum using morphological characteristics were subjected to molecular identification with primers Fg16F (5'-CTCCGGATATGTTGCGTCAA-3') and Fg16R (5'-GGTAGGTATCCGACATGGCAA-3') specific for $F$. graminearum (Nicholson et al. 1998). PCR reaction mixtures were prepared using the method described by Demeke et al. (2005). Briefly, $25 \mathrm{ng}$ of purified DNA was used as template in $25 \mu \mathrm{l}$ reaction mixture containing $1 \times$ PCR buffer $(50 \mathrm{mM} \mathrm{KCl}$, $10 \mathrm{mM}$ Tris-HCl [pH 8.3], $1.5 \mathrm{mM}$ of $\mathrm{MgCl}_{2}$ ), $0.2 \mathrm{mM}$ of each deoxynucleotide triphosphates, $0.4 \mu \mathrm{M}$ of each primer and 0.75 units of Taq DNA polymerase (Thermo Fisher Scientific, Waltham, MA, USA). PCR was performed in a Veriti 96-well Thermal Cycler (AB Applied Biosystems, Foster City, CA, USA). Cycling parameters included: the initial denaturation step set to $3 \mathrm{~min}$ at $95^{\circ} \mathrm{C} ; 38$ cycles consisting of $95^{\circ} \mathrm{C}$ for $30 \mathrm{~s}, 62^{\circ} \mathrm{C}$ for $20 \mathrm{~s}$ and $72^{\circ} \mathrm{C}$ for $45 \mathrm{~s}$, followed by a final extension of $5 \mathrm{~min}$ at $72^{\circ} \mathrm{C}$ and cooling at $4^{\circ} \mathrm{C}$. PCR products were separated by electrophoresis in $1.5 \%$ agarose gels containing $1 \mu \mathrm{g} / \mathrm{ml}$ ethidium bromide. Normalization of 25-line gels was obtained by using 100bp DNA ladder (New England Biolabs, Ipswhich, MA, USA). Using primer pair Fg16F/R. F. graminearum isolates can be classified into six different sequence characterized amplified region (SCAR) types. SCAR type include: type 1 (420 bp), type 2 (510 bp), type 3 (540 bp), type 4 (580 bp), type 5 (520 bp), and type 6 (400 bp) (Carter et al., 2002).

Isolates that were identified as $F$. oxysporum using morphological characteristics were subjected to molecular identification with primer pair FOF1 (5'-ACATACCACTTGTTGCCTCG-3') and FOR1 (5'-CGCCAATCAATTTGAGGAACG-3') specific for $F$. oxysporum (Mishra et al., 2003). In order to increase specificity of FOF1/FOR1 primers we increased annealing temperature by $7^{\circ} \mathrm{C}$ (that is $65^{\circ} \mathrm{C}$ ) comparing with original protocol. As was reported by Jiménez-Fernández et al. (2010) increasing annealing temperature to $65^{\circ} \mathrm{C}$ ensured that no crossamplification would occur with any of the Fusarium spp. that had cross-amplified before. PCR reaction mixtures were prepared as follows: $25 \mathrm{ng}$ of purified DNA was used as template in $25 \mu \mathrm{l}$ reaction mixture containing: $1 \times$ PCR buffer $(50 \mathrm{mM} \mathrm{KCl}, 10 \mathrm{mM}$ Tris- $\mathrm{HCl}$ [pH 8.3], $2 \mathrm{mM}$ of $\mathrm{MgCl}_{2}$ ), $0.2 \mathrm{mM}$ of each deoxynucleotide triphosphates, 0.5 $\mu \mathrm{M}$ of each primer and 1.25 units of Taq DNA polymerase (Thermo Fisher Scientific). PCR was performed in a Veriti 96 well Thermal Cycler (AB Applied Biosystems). Cycling parameters were as follows: an initial denaturation set to 5 min at $94^{\circ} \mathrm{C} ; 30$ cycles consisting of $94^{\circ} \mathrm{C}$ for $1 \mathrm{~min}, 65^{\circ} \mathrm{C}$ for $1 \mathrm{~min}$ and $72^{\circ} \mathrm{C}$ for $1 \mathrm{~min}$, followed by a final extension of $10 \mathrm{~min}$ at $72^{\circ} \mathrm{C}$ and cooling at $4^{\circ} \mathrm{C}$. PCR products were separated by electrophoresis in $1.5 \%$ agarose gels containing $1 \mu \mathrm{g} / \mathrm{ml}$ ethidium bromide. Normalization of 25 -line gels was obtained by using 100-bp DNA ladder (New England Biolabs).

Statistical methods. The factors influencing DI of crown rot of wheat in two growing seasons were analyzed using a multiple stepwise regression. The year, locality, and replicates of sampling were considered as categorical variables, while climatic elements (average temperature, relative humidity, and total rainfall) related with Mačva district $(3,268$ $\mathrm{km}^{2}$ ) for two growing seasons were introduced as continuous variables. Grouping of localities on the basis of difference of the means of DIs was performed using Tukey's pairwise comparisons with the level of confidence of $95 \%$. 
Relationship between standard deviation (SD) and mean of DIs estimated per each locality was identified using linear regression and Spearman's coefficient of correlation. Index of dispersion ( $\mathrm{s}^{2} /$ mean DI) was calculated as a suggestion of data aggregation per each locality (Southwood and Henderson, 2000). Ordinal logistic regression was used to examine if there was significant difference among subsamples within localities in respect to distribution of plants with different score levels (0-9). Descriptive statisitcs was used to summarize means, SDs, and coefficients of variation of DI for examined localites in each growing season. The entire analysis was performed using Minitab 17 (trial version).

\section{Results}

Factors influencing stem-base infestation of winter wheat. Stem-base infestation of winter wheat in two growing seasons differed significantly $(P<0.001)$. The mean value of DI was $49 \%$ in 2014, and $26 \%$ in 2017 (Fig. 1A). DI took the range from 11 to $99 \%$ in 2014, and from 6 to $54 \%$ in 2017 (Fig. 1B).

In order to estimate the most influencing factors on DI in two growing seasons, locality and replicates of sampling (as categorical predictor variables) and climatic elements (as continuous predictor variables) were subjected to multiple stepwise regression. Multiple regression analysis showed that the locality, temperature in January and interaction between growing season and locality had significant influence on DI with $P<0.001$. Replicates of sampling had significant effect on DI with $P=0.024$. The interaction between replicates of sampling and growing season was not neglected $(P=0.131)$ since alpha to enter and alpha to remove the influencing factors in the stepwise regression was set by default to be 0.15 . Multiple regression model accounted for $R^{2}=80 \%$ in variation of DI, indicating that estimated predictor variables greatly contributed to DI variation. The normal probability plot showed an approximately linear pattern (Fig. 2A), and residuals were distributed randomly with no outliers in the data (Fig. 2B) which indicated that model fitted good to the data.

Since the winter temperatures, localities, replicates of sampling, and their interactions with growing season were recognized as significant factors influencing DI of stembase infestation of winter wheat, all of them were further analyzed in more detail.

Influence of climatic elements on DI. In order to investigate the most influencing climatic elements on crown rot of winter wheat, averages of temperature, total rainfall and relative humidity in two growing seasons 2013/2014 and 2016/2017 were subjected to multiple regression analysis as continuous predictor variables. Mean harvest date was 30 June in agro-ecological conditions in Serbia, thus analyzed periods included 1-year intervals between two harvests of each growing season. The most influencing climatic factor on DIs was average temperature in January $(P$ $<0.001)$. The average temperature in January $2017\left(-5.0^{\circ} \mathrm{C}\right)$ was below 10 -year temperature average in Serbia $\left(1.8^{\circ} \mathrm{C}\right)$, while in $2014\left(4.2^{\circ} \mathrm{C}\right)$ it exceeded 10-year average temperature (Fig. 3A). Other climatic elements were not significantly different in two growing seasons except total rainfall
A

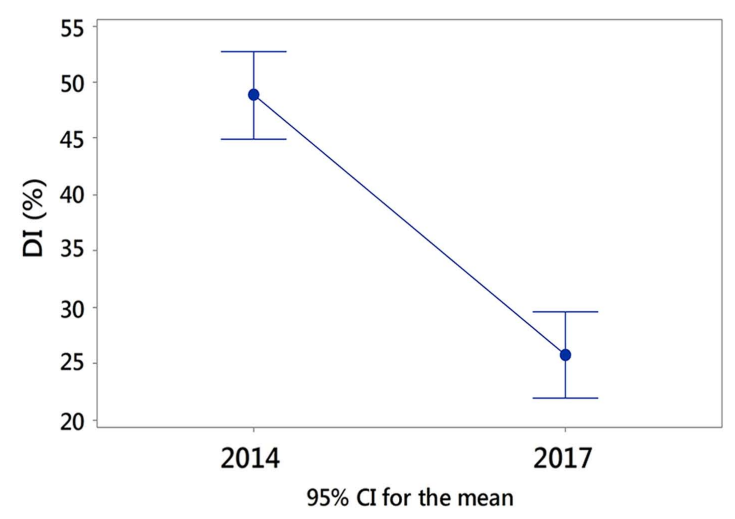

B

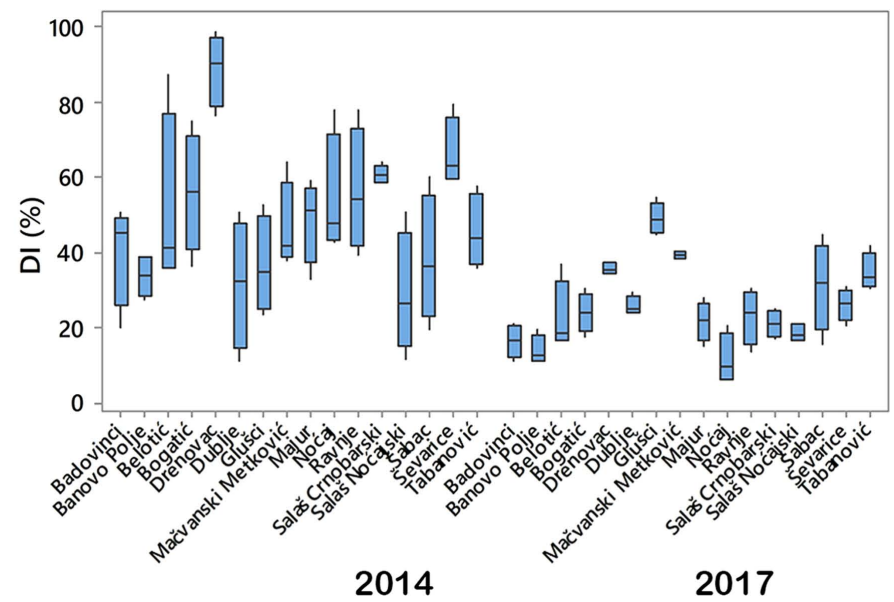

Fig. 1. Disease indices of stem-base infestation in two growing seasons. (A) Plot with confidence intervals of the mean value of disease indices (DIs) in 2014 and 2017. (B) The box plot of DIs in 2014 and 2017 displays the distribution of data based on the five-number summary: minimum, first quartile, median, third quartile, and maximum. Each box was drawn from the first quartile to the third quartile. A vertical line shows the median. CI, confidence interval. 
A

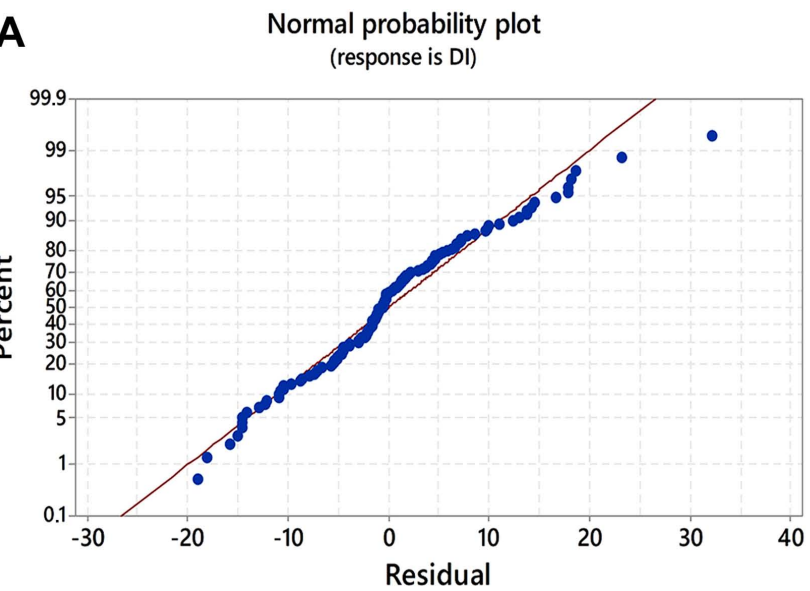

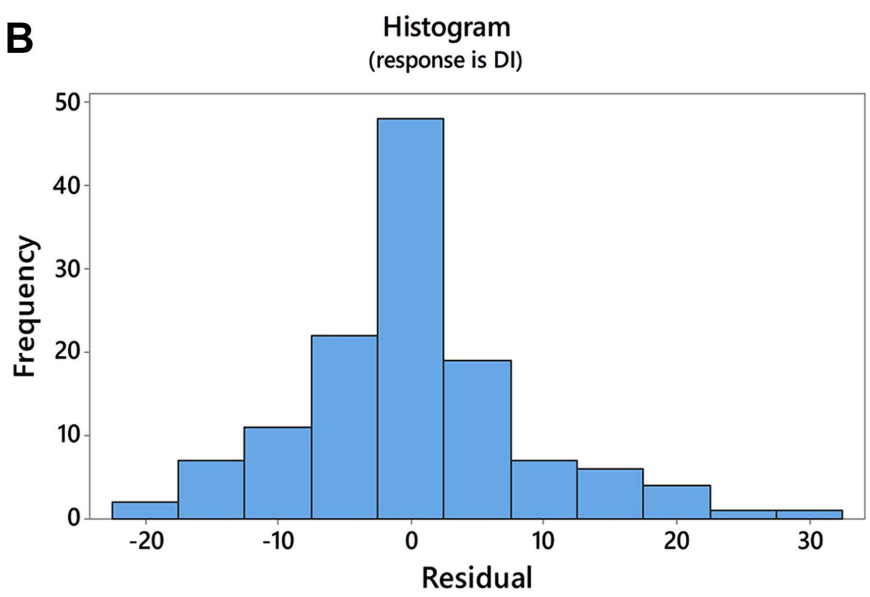

Fig. 2. Residual testing for the normality obtained by multivariate analysis. (A) The normal probability plot shows a linear pattern in residuals consistent with a normal distribution. (B) Histogram of the residuals indicates that there are no outliers in the data. DI, disease index.
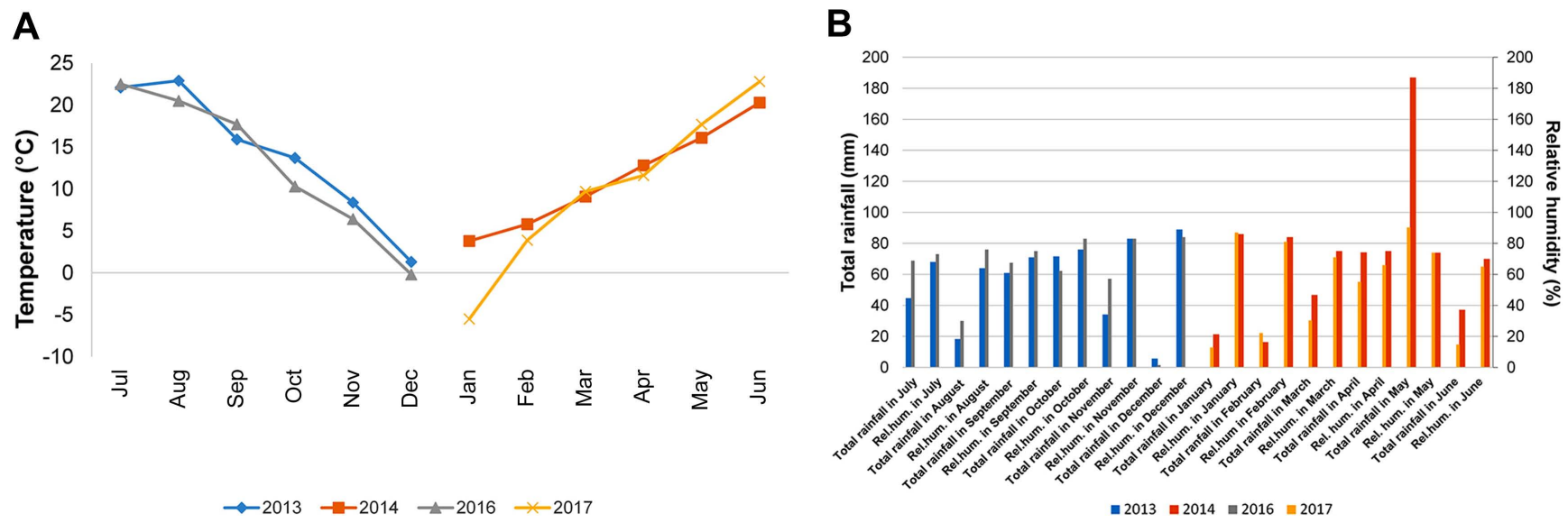

Fig. 3. Climatic conditions for Mačva district in two growing seasons. (A) Average temperatures in July 2013-June 2014 and July 2016June 2017. (B) Relative humidity and total rainfall in July 2013-June 2014 and July 2016-June 2017.

in May $(187 \mathrm{~mm})$ in 2014 which exceeded 10-year average $(102.2 \mathrm{~mm})$ (Fig. 3B). However, this difference did not influence significantly DI estimates in two growing seasons. This result indicated that difference of winter temperatures of nearly $10^{\circ} \mathrm{C}$ in two growing seasons had significant effect on DIs exhibiting in average $49 \%$ in 2014 and $26 \%$ in 2017. The results of this study showed that winter climatic elements should be factored into the studies concerning root and crown rot control management and that more attention should be focused on studies of overwintering capabilities of primary inoculum of Fusarium spp.

Influence of the locality and interaction between growing season and locality on DI. The difference among the means of DIs during a period of two growing seasons was significant, and it was influenced by extremely fluctuating temperatures in winter. However it should be pointed out that localities themselves together with their interaction with the growing season also had significant influence on DIs $(P<0.001)$ (Fig. 4). Localities were grouped on the basis of difference of means of DIs using Tukey pairwise comparisons test at an $\alpha$-level of 0.05 . The highest means of DIs in 2014 were determined in Drenovac (89.0\%), Ševarice (66.1\%), and Salaš Crnobarski (60.6\%). All of them were significantly different (Fig. 4). The highest means of DIs in 2017 were in in Glušci (49.1\%), Metković (39.4\%), and Drenovac (35.7\%) and all of them were also significantly different at an $\alpha$-level of 0.05 (Fig. 4). It should be pointed out that in 2014 all DIs exceeded 29\% regardless of that if localities were positioned near the watercourse or not. In 2017, which was less favorable for crown rot infections, DIs were greater of $29 \%$ only in the three locations (Glušci, Metković, and Drenovac) positioned near the watercourses. These results indicated that 


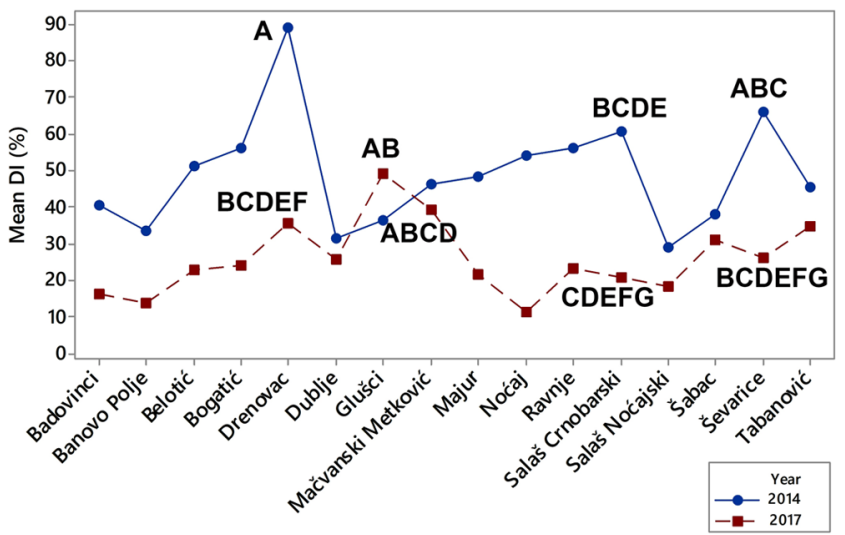

Fig. 4. Influence of the interaction between growing season and locality on disease index (DI). Localities marked with different letters are significantly different.

distance of water sources could greatly contribute to stembase infestation of winter wheat and that it should be considered as a factor in risk model building.

Influence of replicates of sampling and interaction between growing season and replicates of sampling on DI. In order to investigate if distribution of infected plants influences variability of DI estimations, replicates of sampling were factored as categorical variable in multiple regression analysis. It has been shown that replicates of sampling themselves together with their interaction with

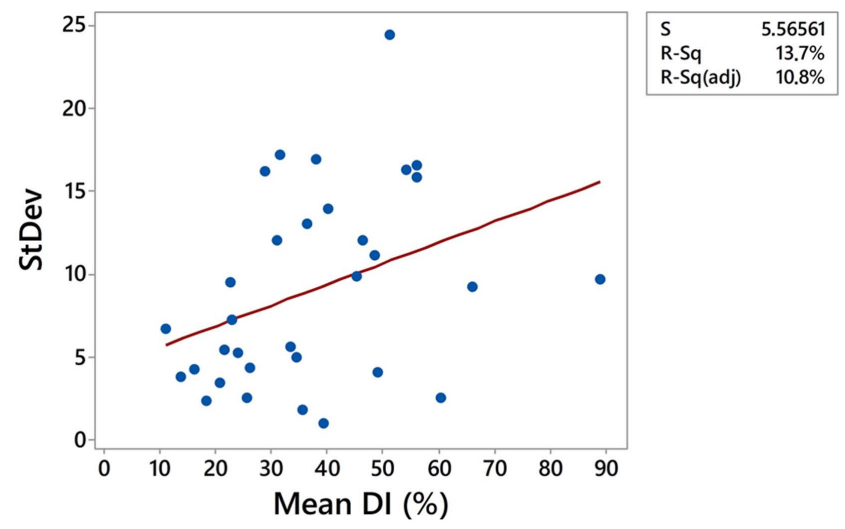

Fig. 5. Regression of standard deviation and mean disease index (DI) in two growing seasons.

the growing season significantly influenced DI estimations. Knowing that the SD is a measure of the variation of DI, differences in SD were analyzed in respect to mean DI, localities, growing seasons and estimates of the aggregation of infected plants.

Relationship between SD and the mean DI in all localities in both growing seasons was analyzed using linear regression and positive association was determined. The positive trend indicated that increment of mean DI would lead in increment of SD (Fig. 5). This result was confirmed by Spearman's coefficient of correlation indicating significant moderate positive correlation between SD and mean

Table 1. Descriptive statistics for DI estimates in two growing seasons

\begin{tabular}{|c|c|c|c|c|c|c|c|c|}
\hline \multirow[b]{2}{*}{ Locality } & \multicolumn{4}{|c|}{2014} & \multicolumn{4}{|c|}{2017} \\
\hline & Mean DI & SD & $\begin{array}{c}\text { Variance } \\
s^{2}\end{array}$ & $\begin{array}{l}\text { Index of } \\
\text { dispersion }\end{array}$ & $\begin{array}{c}\text { Mean } \\
\text { DI }\end{array}$ & $\mathrm{SD}$ & $\begin{array}{c}\text { Variance } \\
s^{2}\end{array}$ & $\begin{array}{l}\text { Index of } \\
\text { dispersion }\end{array}$ \\
\hline Badovinci & 40.3 & 13.9 & 191.9 & 4.7943 & 16.3 & 4.2 & 17.9 & 1.0822 \\
\hline Banovo Polje & 33.5 & 5.6 & 30.8 & 0.9361 & 13.8 & 3.8 & 14.5 & 1.0464 \\
\hline Belotić & 51.2 & 24.4 & 595.6 & 11.6281 & 22.6 & 9.5 & 89.5 & 3.9934 \\
\hline Bogatić & 56.1 & 15.8 & 250.9 & 4.4499 & 24.0 & 5.2 & 26.5 & 1.1267 \\
\hline Drenovac & 89.0 & 9.7 & 93.1 & 1.0572 & 35.7 & 1.8 & 3.2 & 0.0908 \\
\hline Dublje & 31.6 & 17.2 & 295.3 & 9.362 & 25.7 & 2.5 & 6.1 & 0.2432 \\
\hline Glušci & 36.4 & 13 & 167.9 & 4.6429 & 49.1 & 4.1 & 16.9 & 0.3424 \\
\hline Metković & 46.4 & 12 & 141.5 & 3.1034 & 39.4 & 1.0 & 1.0 & 0.0254 \\
\hline Majur & 48.5 & 11.1 & 122.1 & 2.5404 & 21.6 & 5.4 & 28.7 & 1.35 \\
\hline Noćaj & 54.2 & 16.3 & 264.9 & 4.902 & 11.2 & 6.7 & 45.1 & 4.008 \\
\hline Ravnje & 56.3 & 16.6 & 274.3 & 4.8945 & 23.1 & 7.2 & 51.8 & 2.2442 \\
\hline Salaš Crnobarski & 60.6 & 2.5 & 6.0 & 0.1031 & 20.8 & 3.4 & 11.9 & 0.5558 \\
\hline Salaš Noćajski & 28.8 & 16.2 & 263.4 & 9.1125 & 18.4 & 2.3 & 5.3 & 0.2875 \\
\hline Šabac & 38.0 & 16.9 & 285.5 & 7.5161 & 31.0 & 12.0 & 143.7 & 4.6452 \\
\hline Ševarice & 66.1 & 9.24 & 85.4 & 1.2916 & 26.1 & 4.3 & 18.3 & 0.7084 \\
\hline Tabanović & 45.3 & 9.9 & 98.5 & 2.1636 & 34.6 & 5.0 & 24.6 & 0.7225 \\
\hline
\end{tabular}

Bold letters mean that variance $\left(\mathrm{s}^{2}\right)$ was smaller than mean disease index (DI). 
DI $(r=0.4, P=0.024)$. However, it should be pointed out that coefficient of determination of linear regression was $13.7 \%$, which means that only $13.7 \%$ of variation of SD can be explained with variation of the mean DI and that other factors also influenced SD of DI estimates.

Looking on the SDs obtained for 16 localities in two growing seasons it can be noticed that the same sampling method resulted in broad range of SDs estimates, ranging from 2.5 to 24.4 in 2014, and from 1 to 12 in 2017 (Table 1). This indicates that specificity of the localities and growing seasons influenced SD in addition to the level of the pathogen pressure.

Taking into account that variation of SD was influenced not only by variation in mean DI but also by specificity of the localities and growing seasons, index of dispersion $\left(\mathrm{s}^{2} /\right.$ mean DI) was calculated as a suggestion of data aggregation for each locality in both growing seasons (Southwood and Henderson,2000). If index of dispersion was greater than 1 , that was for all localities where variance $\left(\mathrm{s}^{2}\right)$ was greater than mean DI, the aggregation of the infected plants was determined. Also, it was shown that aggregation of infected plants occurred in 14 out of 16 localities in 2013/2014 growing season which was favorable for stembase infection. In 2016/2017 aggregation of infected plants occurred in 8 out of 16 localities (Table 1).

Afterwards it was examined if aggregation of plants with different score levels (0-9) can influence variability in DI estimates. The frequencies of plants with score levels from 0 to 9 obtained from four replicates per each locality and in two growing seasons are presented in Fig. 6.

The relationship between SD and distribution of plants with different score levels was analyzed using the data from the localities showing broad range of SD (2.5-24) related to $2013 / 2014$ growing season since it was favorable for crown rot infection (Fig. 7). Mean DI of analyzed localities took the range from $38 \%$ (Šabac) to $60.6 \%$ (Salaš Crnobarski). It was shown that under pathogen pressure between $38 \%$ to $61 \%$, SD of sampling can be result of aggregation of plants with different levels of stem-base infestation (Fig. 7). Ordinal logistic regression was used to examine if there was significant difference among subsamples within localities in respect to distribution of plants with different score levels. It was shown that in locality Salaš Crnobarski (DI = $61 \%, \mathrm{SD}=2.5$ ) there was no statistical difference among four replicates in respect to distribution of plants with different score levels. $P$-value of all subsamples exceeded 0.686 meaning that subsamples were not significantly related with distribution of plants scored from 0 to 9 . In locality Metković ( $\mathrm{DI}=46.4 \%, \mathrm{SD}=12)$ subsample 3 was significantly different $(P=0.001)$ from the rest of subsamples in respect to distribution of plants scored from 0 to 9. In localities Šabac (DI $=38 \%, \mathrm{SD}=16.9$ ) and Belotić $(\mathrm{DI}=51.2 \%, \mathrm{SD}=24.4)$ all subsamples were significantly different in respect to distribution of plants with different score levels $(P<0.001)$ (Fig. 7).

Those results indicated that aggregation of plants scored with different score levels could influence DI; however, it was also found out that the greatest variability of SD was related with DIs which took the range from $30 \%$ to $60 \%$. This result pointed out that more extensive investigation should be conducted on broad range of DI in order to establish sampling method giving uniform sampling precision.
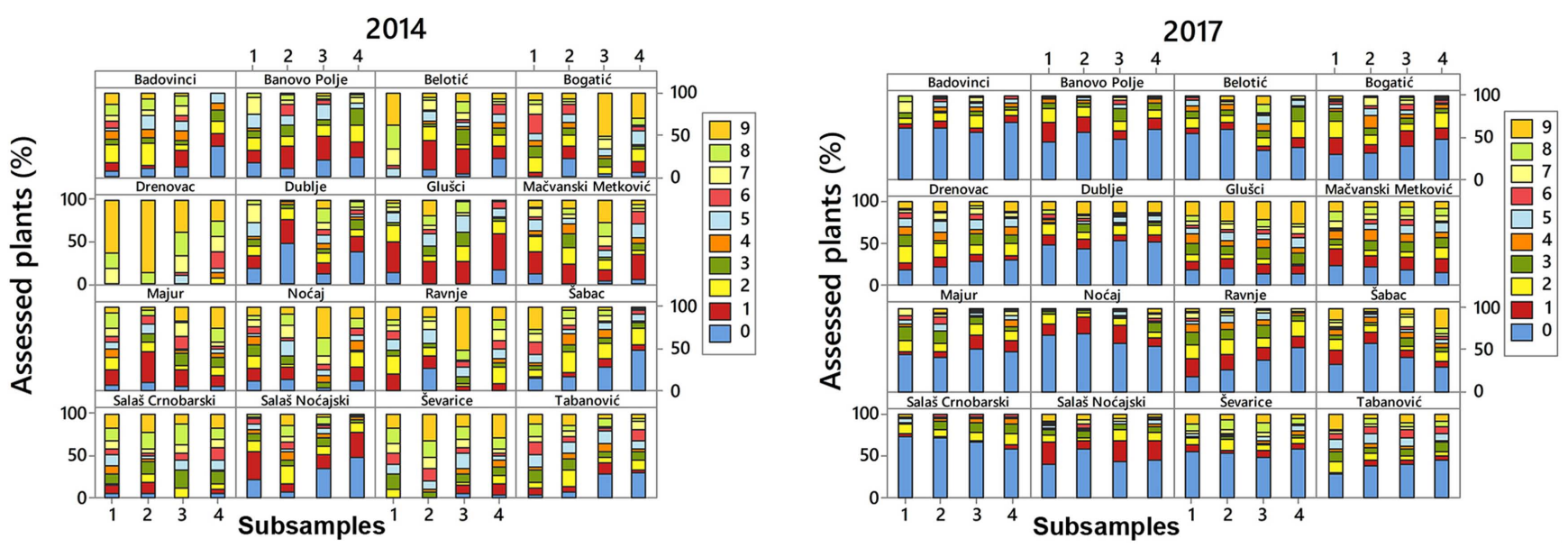

Fig. 6. The divergency of score frequencies among 4 subsamples in each locality in two growing seasons. Scale from 0 to 9 indicates ( 0 , no infected internode; $1,1-10 \%$ infected internode; $2,11-20 \%$ infected internode; $3,21-30 \%$ infected internode; 4, 31-40\% infected internode; 5, 41-50\% infected internode; 6, 51-60\% infected internode; 7, 61-70\% infected internode; 8, 71-80\% infected internode; 9 , $>81 \%$ infected internode). 

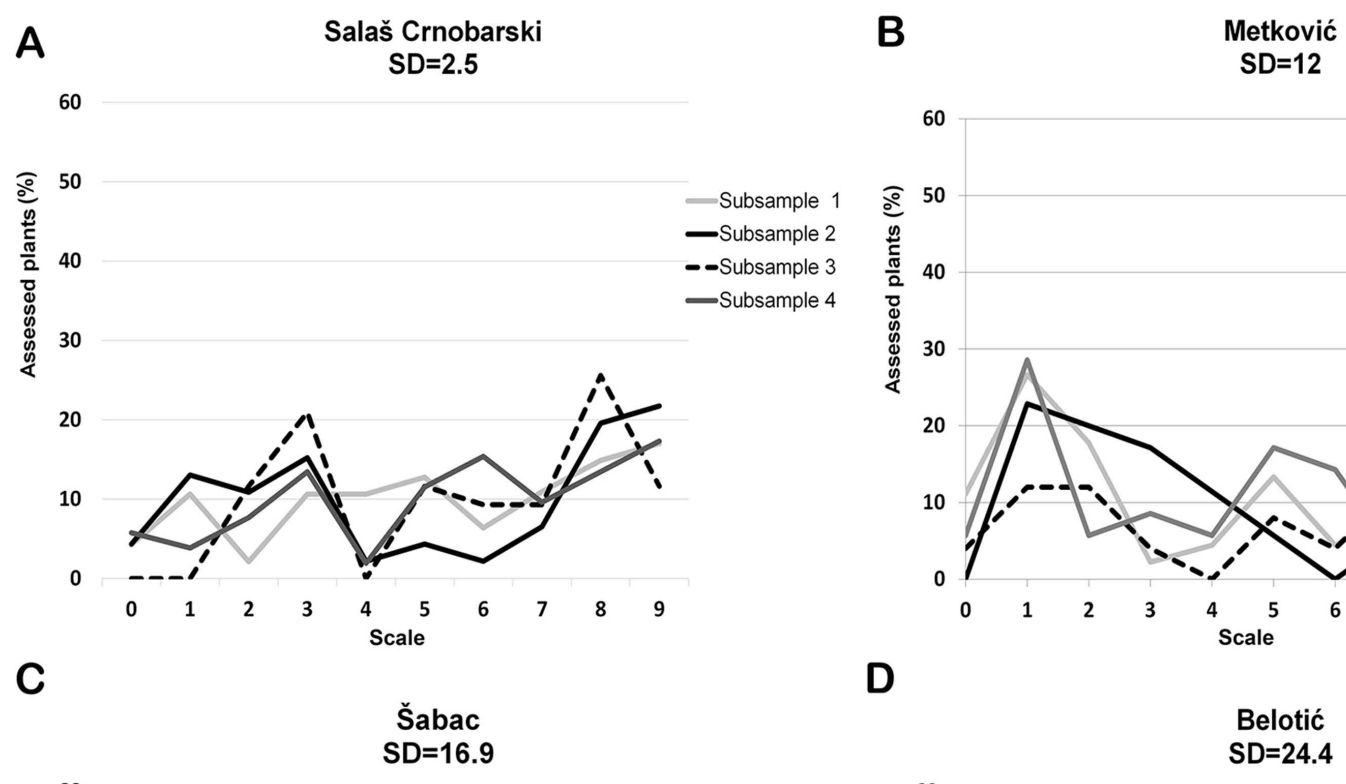

Fig. 7. Distribution of plants with different score levels among four subsamples in localites showing different standard deviations in 2014. Scale from 0 to 9 indicates ( 0 , no infected internode; $1,1-10 \%$ infected internode; $2,11-20 \%$ infected internode; $3,21-30 \%$ infected internode; 4, 31-40\% infected internode; 5, 41-50\% infected internode; 6, 51-60\% infected internode; 7, 61-70\% infected internode; $8,71-80 \%$ infected internode; $9,>81 \%$ infected internode). Difference in percentage frequency of score levels among four subsamples in Salaš Crnobarski (A), Metković (B), Šabac (C), and Belotić (D).

Diversity of Fusarium species causing FCR of wheat under unfavorable climatic condition. In order to examine coexistence of causal agents of FCR under extreme climatic conditions, 62 isolates of Fusarium species isolated in 2016/2017 were identified using species-specific PCR (SCAR analysis). Molecular analysis showed that $F$. graminearum was dominant Fusarium species in Serbia in 2016/2017 with frequency of $72.6 \%$ (45/62). SCAR analysis revealed that all isolates of $F$. graminearum belong to SCAR group 1 producing PCR product of $420 \mathrm{bp}$ (Fig. 8A). Isolates of $F$. oxysporum produced PCR product of $340 \mathrm{bp}$ and were identified with frequency of $27.4 \%$ (17/62) (Fig. 8B).
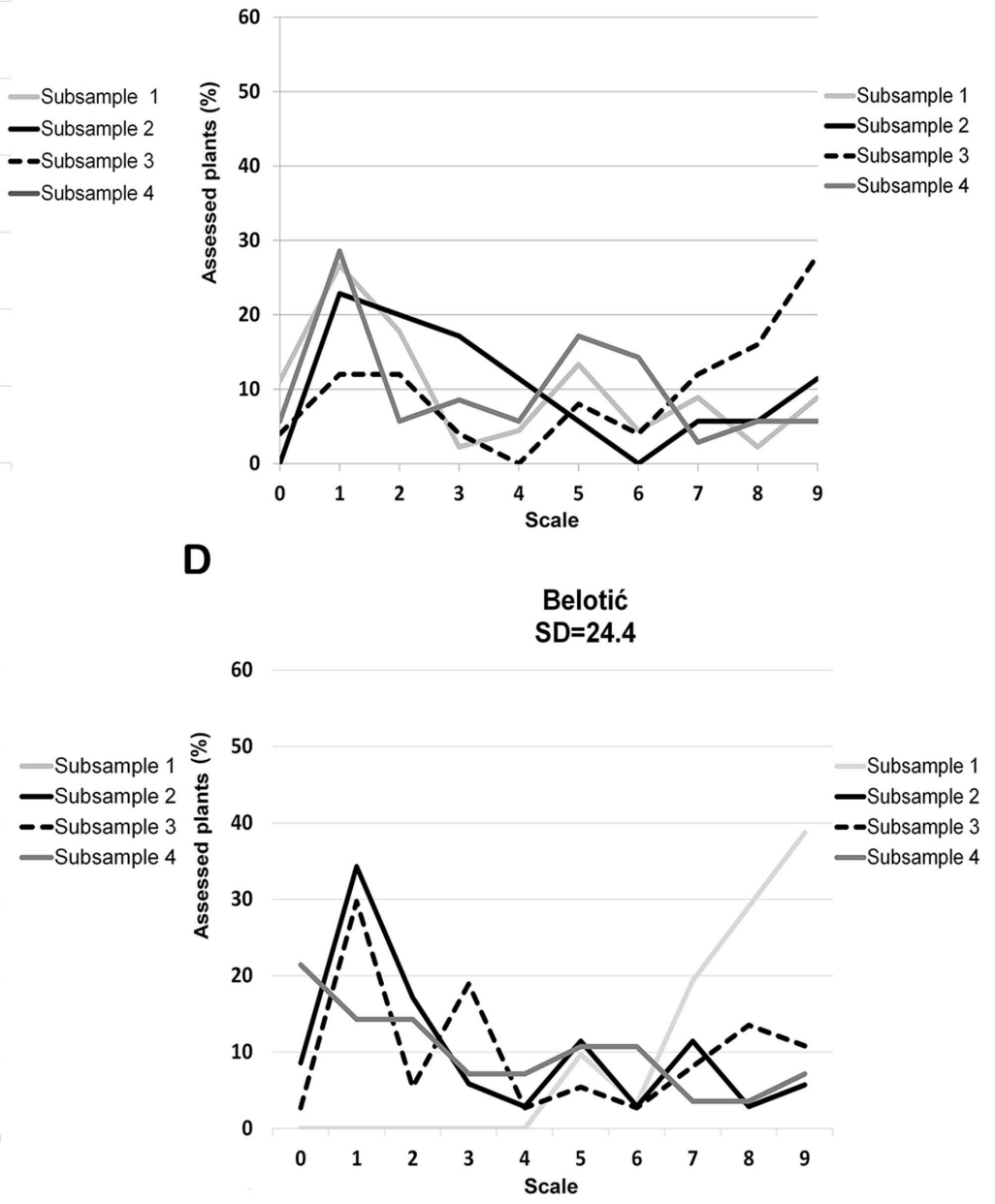

D
The visual score of symptoms of causal agents of crown rot and isolated pathogens were not fully in agreement. $F$. graminearum identified by SCAR analysis was isolated not only from stem-bases showing FCR symptoms but also from stem-bases with symptoms characteristic for eyespot and take-all. $F$. oxysporum was also isolated not only from stem-bases showing FCR symptoms but also from plant with symptoms of eyespot and take-all. Symptoms of FCR were not typical in all plant form which $F$. graminearum and $F$. oxysporum were isolated. Only $75.6 \%$ of plants from which $F$. graminearum was isolated had typical FCR symptoms. F. oxysporum was isolated from 17 plants, but only 9 of them showed symptoms of FCR. 

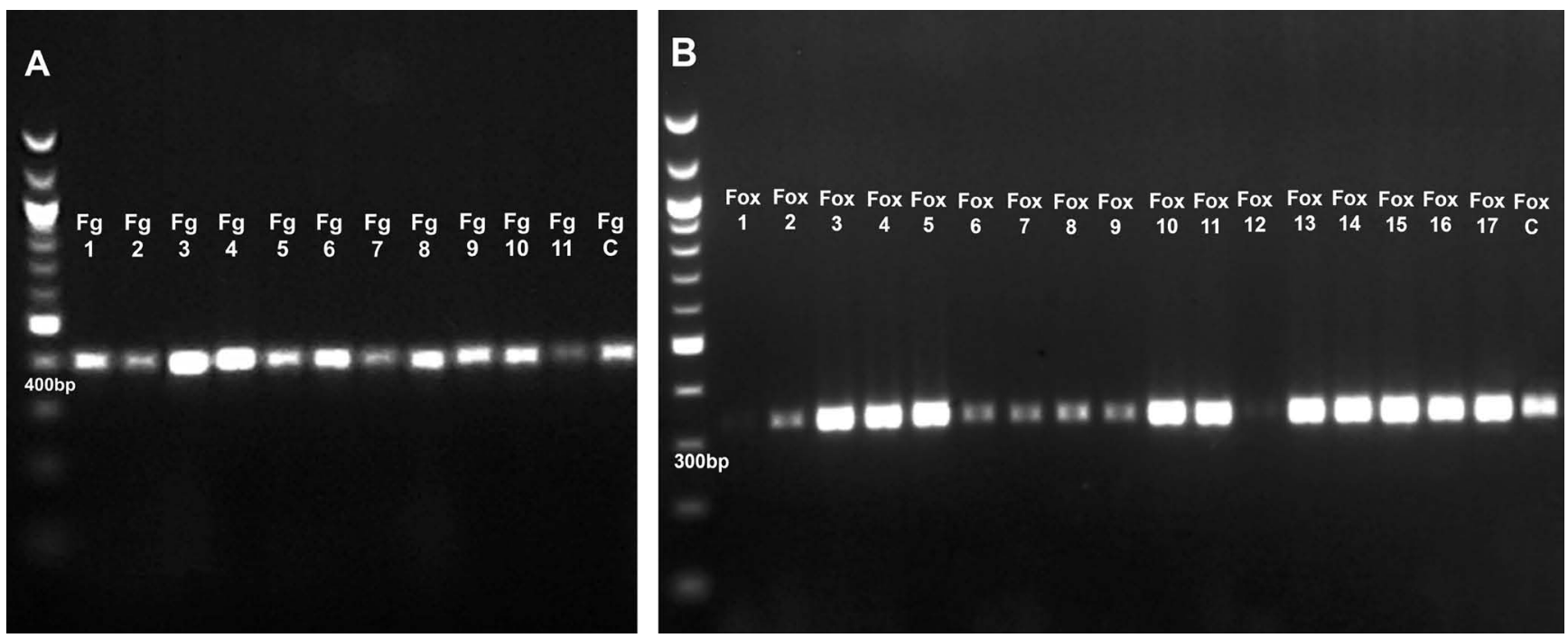

Fig. 8. PCR products of Fusarium species sampled in 2017. (A) Isolates identified as F. graminearum. Fg1-Fg11, PCR products of Fg16F/R primer pair specific for F. graminearum, FgC-Control isolate of F. graminearum. (B) Isolates identified as F. oxysporum. Fox1-Fox17, PCR products of FOF1/FOR1 primer pair specific F. oxysporum, FoxC-Control isolate of F. oxysporum.

\section{Discussion}

Grain quality assurance and high yield achievements are the major preconditions for efficient plant production. Until now, many efforts have been made to develop effective control strategies against causal agents of FHB, but investigations related to Fusarium species causing root and crown rot were underestimated (Wang et al., 2015). The relationship among species that causes root and crown rot of wheat and their coexistence in field conditions are also hardly known, and the effectiveness of root and crown rot management was shown to be unpredictable since certain agronomic practice might favor one pathogen while causing a reduction of another (Fernandez and Conner, 2011). Consequently, in this study the influence of environmental factors on variability of stem base infestation of wheat was analyzed in respect to disease complex as whole.

There are many reports on predominance of causal agents of root and crown rot in different geographic regions. However the effect of climate change on diversity and pathogenicity of causal agents of root and crown rot have yet to be investigated. It was reported that there was a shift in predominant Fusarium species causing FHB in north Europe and north-western Russia (Waalwijk et al., 2003; Yil-Mattila, 2010) as a result of climate change, but these studies did not analyze the effects of climate change on possible fluctuations in population of Fusarium spp. that causes FRR and FCR. Although it was reported that causal agents of crown rot of wheat are less affected by environmental conditions than those causing spike infections (Fernandez and Conner, 2011), it was demonstrated in this study that fluctuations in climatic elements together with their interactions with localities can affect the level of crown rot infestation and in consequence can jeopardize wheat production.

Specifically, fluctuations in winter temperatures significantly affected disease index of crown rot of wheat in agro-ecological conditions in Serbia. In general, the investigations related to impact of winter climatic elements on FHB occurrence have been rare and there are only few publications which raise the question on the overwintering capabilities of primary inoculum of Fusarium spp. (Aldred and Magan, 2004; Landschoot et al., 2012; Manstretta and Rossi, 2016). In this study, potentials of $F$. graminearum to cause FCR in years with unfavorable climatic conditions were proven, and knowing that $F$. graminearum can contribute to the inoculum preservation (Fernandez and Conner, 2011), results of our study pointed out that winter climatic elements should be factored into the studies concerning $F$. graminearum control management.

In addition, DI estimates were significantly influenced by replicates of sampling themselves and their interaction with the growing season. It was shown that pathogen pressure was not the only factor influencing SD of DI estimates and aggregation of infected plants was also the factor influencing DI estimates. SD as a measure of variability of DI estimates took the broad range among sixteen localities using the same sampling method, and the greates variability of SD was related with DIs ranging from $30 \%$ to $60 \%$. 
Similarly as was reported by Župunski et al. (2017) that the same sampling method would not result in similar precision of population density estimation if applied on medium and high contamination level of cyst nematodes, the results of this study pointed out that more extensive investigation should be conducted on sampling precision testing which was rather underestimated in previous studies related with crow rot infestation assessments.

Another objective in this study was to analyze coexistence of Fusarium species causing FCR under extreme climatic condition and it was shown by SCAR analysis that $F$. graminearum predominated as causal agent of FCR over the other Fusarium spp. with the frequency of $72.6 \%$. The agreement between symptoms assessed by visual stem-base scoring, and the identified $F$. graminearum using molecular technique was $75.6 \%$. Since it was reported that fungal species that tended to correlate better with symptoms are the more aggressive pathogens (Matusinsky et al., 2008), $F$. graminearum can be considered as the predominant causal agent of crown rot of winter wheat in agro-ecological conditions of Mačva district which is one of the main wheatgrowing area in Serbia. Interestingly, the percent of $F$. oxsysporum that was identified by SCAR analysis (27.4\%) was much greater than those reported in the literature. In the study of Tyburski et al. (2014) F. oxysporum originated from 3.8\% isolates of stem-base of wheat collected in BBCH 83-87. Other authors reported lower percent of $F$. oxysporum isolated from the stem-base in dough grain stage $(0.5 \%)$ or in later growth stages $(2.1 \%)$ (Moya-Elizondo et al., 2015; Xu et al., 2018). In addition, F. oxysporum is mainly reported as saprophyte or as the species with low pathogenic potentials (Moya-Elizondo et al., 2015). Frequency of $F$. oxysporum isolated from stem-base in this study indicated that in the years which are not favorable for crown rot infection, $F$. oxysporum could have impact on wheat production through both pathogenic and saprophytic potentials. This finding is supported by the results reported by Leplat et al. (2013) who noted that $F$. oxysporum has better saprotrophic capacity than $F$. graminearum and that it would be expected that the amount of $F$. graminearum found on wheat residues rapidly decreases whereas those of $F$. oxysporum increase. The risk of controlling Fusarium spp. causing FCR is also accentuated by Marburger et al. (2015) who noted that none of the management strategies employed in their study significantly reduced $F$. oxysporum.

Results of our study contribute to the general knowledge of factors influencing relationship between Fusarium spp. causing crown rot of wheat. It also addressed the need for investigations that would consider combined effects of abi- otic and biotic factors influencing stem-base infestation of winter wheat in order to better understand and predict risks of FHB, FRR, and FCR outbreaks which would ensure sustainable wheat production and disease management in the future.

\section{Acknowledgments}

This study was also funded as part of the project TR 31066 - Contemporary breeding of small grains for current and future needs financed by the Ministry of Education, Science and Technological Development of the Republic of Serbia.

\section{References}

Agrios, G. N. 1997. Plant pathology. 4th ed. Academic Press, London, UK. 635 pp.

Aldred, D. and Magan, N. 2004. Prevention strategies for trichothecenes. Toxicol. Lett. 153:165-171.

Barnett, H. L. and Hunter, B. B. 1972. Illustrated genera of imperfect fungi. 3rd ed. Burgess Publishing Co., Minneapolis, MN, USA. $241 \mathrm{pp}$.

Carter, J. P., Rezanoor, H. N., Holden, D., Dejardins, A. E., Plattner, R. D. and Nicholson, P. 2002. Variation in pathogenicity associated with the genetic diversity of Fusarium graminearum. Eur. J. Plant Pathol. 108:537-583.

Demeke, T., Clear, R. M., Patrick, S. K. and Gaba, D. 2005. Species-specific PCR-based assays for the detection of Fusarium species and a comparison with the whole seed agar plate method and trichothecene analysis. Int. J. Food Microbiol. 103:271-284.

de Mol, F., Winter, M. and Gerowitt, B. 2018. Weather determines the occurrence of wheat stem base diseases in biogas cropping systems. Crop Prot. 114:1-11.

Fernandez, M. R. and Conner, R. L. 2011. Root and crown rot of wheat. Prairie Soils Crops J. 4:151-157.

Jiménez-Fernández, D., Montes-Borrego, M., Navas-Cortés, J. A., Jiménez-Díaz, R. M. and Landa, B. B. 2010. Identification and quantification of Fusarium oxysporum in planta and soil by means of an improved specific and quantitative PCR assay. Appl. Soil Ecol. 46:372-382.

Jevtić, R., Panković, L. and Jerković, Z. 2006. Causal agents of root and stem base rot of wheat. Zb. Rad. 42:415-419 (in Serbian).

Landschoot, S., Waegeman, W., Audenaert, K., Vandepitte, J., Baetens, J. M., De Baets, B. and Haesaert, G. 2012. An empirical analysis of explanatory variables affecting Fusarium head blight infection and deoxynivalenol content in wheat. $J$. Plant Pathol. 94:135-147.

Leplat, J., Friberg, H., Abid, M. and Steinberg, C. 2013. Survival of Fusarium graminearum, the causal agent of Fusarium head blight: a review. Agron. Sustain. Dev. 33:97-111.

Leslie, J. F. and Summerell, B. A. 2006. The Fusarium laboratory 
manual. Blackwell Publishing, Ames, IA, USA. 388 pp.

Lević, J., Stanković, S., Krnjaja, V., Tančić, S., Ivanović, D. and Bočarov-Stančić, A. 2012. Relationships of mycobiota on rachides and kernels of wheat. Eur. J. Plant Pathol. 134:249256.

Manstretta, V. and Rossi, V. 2016. Effects of temperature and moisture on development of Fusarium graminearum perithecia in maize stalk residues. Appl. Environ. Microbiol. 82:184191.

Marburger, D. A., Venkateshwaran, M., Conley, S. P., Esker, P. D., Lauer J. G. and Ané, J.-M. 2015. Crop rotation and management effect on Fusarium spp. populations. Crop Sci. 55:365376.

Matusinsky, P., Mikolasova, R., Klem, K., Spitzer, T. and Urban, T. 2008. The role of organic vs. conventional farming practice, soil management and preceding crop on the incidence of stem-base pathogens on wheat. J. Plant Dis. Prot. 115:17-22.

Mishra, P. K., Fox, R. T. V. and Culham, A. 2003. Development of a PCR-based assay for rapid and reliable identification of pathogenic Fusaria. FEMS Microbiol. Lett. 218:329-332.

Möller, E. M., Bahnweg, G., Sandermann, H. and Geiger, H. H. 1992. A simple and efficient protocol for isolation of high molecular weight DNA from filamentous fungi, fruit bodies, and infected plant tissues. Nucleic Acids Res. 20:6115-6116.

Moya-Elizondo, E., Arismendi, N., Castro, M. P. and Doussoulin, H. 2015. Distribution and prevalence of crown rot pathogens affecting wheat crops in southern Chile. Chil. J. Agric. Res. 75:78-84.

Nicholson, P., Simpson, D. R., Weston, G., Rezanoor, H. N., Lees, A. K., Parry, D. W. and Joyce, D. 1998. Detection and quantification of Fusarium culmorum and Fusarium graminearum in cereals using PCR assays. Physiol. Mol. Plant Pathol. 53:17-37.

Paulitz, T. C. 2010. Take-all. In: Compendium of wheat diseases and pests, 3rd ed., eds. by W. W. Bockus, R. L. Bowden, R. M. Hunger, W. L. Morrill, T. D. Murray and R.W. Smiley, pp. 7982. American Phytopathological Society, St. Paul, MN, USA.

Poole, G. J., Smiley, R. W., Walker, C., Huggins, D., Rupp, R., Abatzoglou, J., Garland-Campbell, K. and Paulitz, T. C. 2013. Effect of climate on the distribution of Fusarium spp. causing crown rot of wheat in the Pacific Northwest of the United States. Phytopathology 103:1130-1140.

Smiley, R. W., Gourlie, J. A., Easley, S. A., Patterson, L. M. and
Whittaker, R. G. 2005. Crop damage estimates for crown rot of wheat and barley in the Pacific Northwest. Plant Dis. 89:595-604.

Smiley, R. W. and Patterson, L. M. 1996. Pathogenic fungi associated with Fusarium foot rot of winter wheat in the semiarid Pacific Northwest. Plant Dis. 80:944-949.

Southwood, T. R. E. and Henderson, P. A. 2000. Ecological methods. 3rd ed. Blackwell Science, Oxford, UK. 575 pp.

Stošić, N., Jevtić, R., Lalošević, M., Župunski, V. and Maširević, S. 2016. Root and stem rot of wheat: causal agents and control. Biljni Lekar 44:408-416 (in Serbian).

Townsend, G. R. and Heuberger, J. W. 1943. Methods for estimating losses caused by diseases in fungicide experiments. Plant Dis. Rep. 27:340-343.

Tyburski, J., Kurowski, T. and Adamiak, E. 2014. Root and foot rot diseases of winter wheat grown in conventional and organic systems. J. Agric. Chem. Environ. 3:1-8.

Waalwijk, C., Kastelein, P., de Vries, I., Kerényi, Z., van der Lee, T., Hesselink, T., Köhl, J. and Kema, G. 2003. Major changes in Fusarium spp. in wheat in the Netherlands. Eur. J. Plant Pathol. 109:743-754.

Wang, Q., Vera Buxa, S., Furch, A., Friedt, W. and Gottwald, S. 2015. Insights into Triticum aestivum seedling root rot caused by Fusarium graminearum. Mol. Plant-Microbe Interact. 28:1288-1303.

Westra, S., Fowler, H. J., Evans, J. P., Alexander, L. V., Berg, P., Johnson, F., Kendon, E. J., Lenderink, G. and Roberts, N. M. 2014. Future changes to the intensity and frequency of shortduration extreme rainfall. Rev. Geophys. 52:522-555.

Wildermuth, G. B. and McNamara, R. B. 1994. Testing wheat seedlings for resistance to crown rot caused by Fusarium graminearum Group 1. Plant Dis. 78:949-953.

Xu, F., Yang, G., Wang, J., Song, Y., Liu, L., Zhao, K., Li, Y. and Han, Z. 2018. Spatial distribution of root and crown rot fungi associated with winter wheat in the North China Plain and its relationship with climate variables. Front. Microbiol. 9:1054.

Yli-Mattila, T. 2010. Ecology and evolution of toxigenic Fusarium species in cereals in Northern Europe and Asia. J. Plant Pathol. 92:7-18.

Župunski, V., Jevtić, R., Jokić, V. S., Župunski, L., Lalošević, M., Ćirić, M. and Ćurčić, Ž. 2017. Sampling error in relation to cyst nematode population density estimation in small field plots. J. Nematol. 49:150-155. 